\title{
Cortical thickness and formal thought disorder in schizophrenia: An ultra high-field network-based morphometry study
}

Lena Palaniyappan ${ }^{1,2,3}$, Ali Al-Radaideh ${ }^{4,5}$, Penny A. Gowland ${ }^{5}$, Peter F. Liddle ${ }^{6}$.

\author{
AFFILIATIONS: \\ ${ }^{1}$ Robarts Research Institute, University of Western Ontario, London, Ontario, Canada \\ ${ }^{2}$ Department of Psychiatry, University of Western Ontario, London, Ontario, Canada \\ ${ }^{3}$ Lawson Health Research Institute, London, Ontario, Canada. \\ ${ }^{4}$ Department of Medical Imaging, Faculty of Allied Health Sciences, The Hashemite \\ University, Zarqa, Jordan. \\ ${ }^{5}$ Sir Peter Mansfield Imaging Centre (SPMIC), School of Physics and Astronomy, \\ University of Nottingham, Nottingham, UK. \\ ${ }^{6}$ Translational Neuroimaging for Mental Health, Division of Psychiatry and Applied \\ Psychology, University of Nottingham, Nottingham, UK.
}

Number of words: Abstract: 249, Article (incl. figure captions): 3205, Figures: 3, Tables: 2

Address correspondence to: Dr. Lena Palaniyappan, Room-A2/636, Program for Prevention and Early Intervention in Psychoses, Victoria Hospital, 800, Commissioners Road, London, ON. Canada Email: Ipalaniy@uwo.ca

Funding information: This work was supported by the Wellcome Trust [grant number WT096002/Z/11] and an internal grant from the School of Community Health Sciences, University of Nottingham. LP is supported by the Tanna Schulich Endowment, Academic Medical Organization of South-Western Ontario (Opportunities Fund), Bucke Funds, and Chrysalis Foundation Funds. PFL receives support from the National Institute of Health Research Nottingham Biomedical Research Centre.

Conflicts of interest: LP reports personal fees from Janssen, Otsuka Canada, Canadian Psychiatric Association and SPMM Course (UK); investigator-initiated educational grants from Sunovion, Janssen Canada, Otsuka Canada not related to the submitted work. Other authors report no relevant conflicts.

Key words: Disorganisation, thought disorder, Salience Network, Cognitive Control, Language Network, coherence 


\begin{abstract}
Background: Persistent formal thought disorder (FTD) is a core feature of schizophrenia. Recent cognitive and neuroimaging studies indicate a distinct mechanistic pathway underlying the persistent positive FTD ( $\mathrm{FFTD}$ or disorganized thinking), though its structural determinants are still elusive. Using network-based cortical thickness estimates from ultra-high field 7-Tesla Magnetic Resonance Imaging (7T MRI), we investigated the structural correlates of pFTD.
\end{abstract}

Methods: We obtained speech samples and 7T MRI anatomical scans from medicated clinically stable patients with schizophrenia $(n=19)$ and healthy controls $(n=20)$. Networkbased morphometry was used to estimate the mean cortical thickness of 17 functional networks covering the entire cortical surface from each subject. We also quantified the vertexwise variability of thickness within each network to quantify the spatial coherence of the 17 networks, estimated patients vs. controls differences, and related the thickness of the affected networks to the severity of pFTD.

Results: Patients had reduced thickness of the frontoparietal and default mode networks, and reduced spatial coherence affecting the salience and the frontoparietal control network. A higher burden of positive FTD related to reduced frontoparietal thickness and reduced spatial coherence of the salience network. The presence of positive FTD, but not its severity, related to the reduced thickness of the language network comprising of the superior temporal cortex.

Conclusions: These results suggest that cortical thickness of both cognitive control and language networks underlie the positive FTD in schizophrenia. The structural integrity of cognitive control networks is a critical determinant of the expressed severity of persistent FTD in schizophrenia. 


\section{Introduction}

Formal thought disorder (FTD) is a core clinical feature of schizophrenia (Jerónimo et al., 2018). Presence of FTD predicts transition to psychosis in individuals at high risk of schizophrenia, predating the actual onset by several years (Bearden et al., 2011; Demjaha et al., 2017; DeVylder et al., 2014; Gooding et al., 2013; Wilcox et al., 2014). FTD is also indicative of higher illness severity (Roche et al., 2015) and poor sociooccupational outcomes (Roche et al., 2016) in first episode psychosis. While FTD seen in acute psychosis often resolves with time, persistence of FTD in those with established illness affects therapeutic alliance (Cavelti et al., 2016), social functioning (Palaniyappan et al., 2019b; Sousa et al., 2019) and occupational recovery (Harrow and Marengo, 1986), thus reducing the overall quality of life (Tan et al., 2014; Ulas et al., 2008). Despite this, our current understanding of the mechanistic basis of FTD is limited and treatment approaches are elusive (Kircher et al., 2018).

Two recent state-of-art syntheses in FTD highlight the substantial inconsistencies in the neuroimaging observations reported to date (Cavelti et al., 2018a; Sumner et al., 2018a). While functional MRI studies often employ linguistic tasks that preferentially implicate language network in FTD (Cavelti et al., 2018a; Sumner et al., 2018b; Wensing et al., 2017), structural MRI studies report more distributed abnormalities in both the language network and non-language specific networks (Cavelti et al., 2018a; Sumner et al., 2018a). In particular, the two distinct domains of FTD - positive FTD (characterised by looseness, peculiar word/sentence or illogicality) and negative FTD (characterised by reduced fluency, speed and content) - are thought to have distinct neurocognitive correlates (Bora et al., 2019; Tan and Rossell, 2017) but are not often parsed in neuroimaging studies. A small number of studies that parse these 2 dimensions identify structural deficits that extend beyond the language network (Palaniyappan et al., 2015; Sans-Sansa et al., 2013) in negative FTD. Nevertheless, the structural basis of positive FTD continues to be elusive in most studies (Cavelti et al., 2018b; Palaniyappan et al., 2015; Winkelbeiner et al., 2018; but see Sans-Sansa et al., 2013).

The mechanistic basis of positive FTD is particularly challenging to elucidate as the clinical features are often subtle (Cohen et al., 2017; Sommer et al., 2010), fluctuate with acute psychotic symptoms ( $\mathrm{Li}$ et al., 2019) and easily missed during cross-sectional clinical interviews (de Bruin et al., 2007; Palaniyappan, 2009). Furthermore, most morphometric studies in FTD quantify the composite measure of grey matter volume (except (Winkelbeiner et al., 2018)). Cortical thickness is much more sensitive morphological metric that provides insights into dynamic structural remodeling related to longitudinal changes in symptom trajectories (Guo et al., 2016; Palaniyappan et al., 2019a)). While volume changes may result from non-specific morphometric effects (Palaniyappan and Liddle, 2012; Panizzon et al., 2009), thickness changes are increasingly linked to intracortical myelination and dendritic spine branching (Shin et al., 2018; Storsve et al., 2014), thus enabling us to hone in on cellular processes underlying 
the suspected structural changes in FTD (Kircher et al., 2018). There are no whole brain studies relating cortical thickness to FTD to date.

The thickness of cerebral cortex varies across individuals as well as across different cortical regions within an individual. Across subjects, the cortical thickness of one region of a functional network co-varies tightly with other regions that constitute the functional network possibly due to shared trophic influences and/or coordinated maturational programming (Alexander-Bloch et al., 2013b, 2013a). Spatially distributed regions within a defined functional network show consistent task-related recruitment, which can also have a plastic influence on the observed structural covariance (Kelly and Castellanos, 2014). At an individual level, pathological processes disrupting this maturational or functional coherence can result in higher than expected degree of variability within largescale networks (Kong et al., 2019, 2014), resulting in spatial incoherence. Interestingly, patients with schizophrenia show both relative thinning and thickening of cortex when compared to controls, in functionally linked brain regions (e.g. thinning of posterior cingulate, but thickening of precuneus, within the same default-mode network as shown by van Erp et al., 2018), which can result in increased spatial incoherence within functional networks. We quantified the network-level thickness and its spatial incoherence in 17 cortical networks covering the entire cortical surface, identified on the basis of well-replicated patterns of intrinsic connectivity (Yeo et al., 2011).

The aim of the present study was to investigate if the severity of positive FTD varies with illness-related changes in cortical thickness in schizophrenia. To this end we utilised the same sample previously reported (in Palaniyappan et al., 2015) to first delineate the cortical networks showing significant thinning and spatial incoherence in patients with schizophrenia compared to healthy controls. We then studied if positive FTD was associated with the thickness and coherence of the affected cortical networks. Given the prior findings implicating language networks in FTD (Kircher et al., 2018), we investigated if structural changes in language networks showing intrinsic functional connectivity independently explain the variance in the severity of positive FTD, in addition to the illness-related morphometric changes. 


\section{Methods}

\section{Participants}

20 patients receiving community based care for a Diagnostic and Statistical Manual of Mental Disorders (DSM)-IV (American Psychiatric Association, 1994) diagnosis of schizophrenia were specifically recruited in a stable phase of illness for this study. Patient volunteers who only satisfied 295.40 Schizophreniform Disorder criteria were not included. 21 healthy controls group matched for age, gender and parental socioeconomic status (measured using National Statistics - Socio Economic Classification (Rose and Pevalin, 2003)) were also recruited. 1 patient and 1 control were excluded due to motion artifacts affecting cortical surface reconstruction. Subjects with neurological disorders, current substance dependence, or intelligence quotient $(I Q)<70$ (Ammons and Ammons, 1962) were excluded. Healthy subjects were also excluded if there was a personal or family history of psychosis. All subjects were recruited from the county of Nottinghamshire, UK with informed consent to participate obtained in accordance with the approval from the National Research Ethics Committee, Nottinghamshire.

\section{Clinical Assessment}

The diagnosis was made through a consensus procedure as per Leckman et al., (1982), using multiple sources of information including clinical notes, information provided by treating clinicians as well a structured diagnostic interview (Liddle et al., 2002). The clinical stability was assessed as $<10$ points change in Global Assessment of Function [GAF, DSM-IV (American Psychiatric Association, 1994)] score in the 6 weeks prior to study participation.

Patents and healthy controls were interviewed on the same day as the scan using the validated procedure for administering Thought Language Index (Liddle et al., 2002). Subjects were asked to describe 3 pictures from Thematic Apperception Test (Murray, 1943), for one minute each, with follow-up questions raised by the interviewer if needed. The free speech samples were recorded and later transcribed by a team member with no direct contact with the subject and blind to the diagnostic status, symptom burden and neuroimaging findings (See Supplement). Positive FTD was defined as the summed score of looseness, peculiar word, peculiar sentence and peculiar logic were classified as positive FTD while the scores of perseveration, poverty of speech and weakening of goal were summed as negative FTD, as in our previous study (Palaniyappan et al., 2015). All patients in our sample had English as their first language.

Handedness was assessed using the 12-items Annett scale (Annett, 1970). The median defined daily dose (DDD) of antipsychotics (WHO Collaborating Centre for Drug Statistics and Methodology, 2003) was calculated for all patients using the World Health 
Organisation databse (http://www.whocc.no/). If a patient received more than one antipsychotic, the respective DDD values were summed.

\section{MRI acquisition and processing}

The procedures for MRI acquisition are described in our previous report (Palaniyappan et al., 2015). In summary, T1 weighted images were acquired from a 7T Philips Achieva (32-channel coil) using a 3D Magnetization Prepared-Turbo Field Echo (IR-TFE) with $0.6 \mathrm{~mm}$ isotropic resolution, $192 \times 180 \times 140 \mathrm{~mm}$ matrix, TR $=15 \mathrm{~ms}$, TE $=5.6 \mathrm{~ms}$, shot interval $=3 \mathrm{~s}$, and flip angle $8^{\circ}$. Bias field inhomogeneity was reduced using an optimized inversion pulse (adiabatic pulse). We have previously shown that in this sample, the total grey matter tissue volume estimated from the $3 \mathrm{~T}$ and $7 \mathrm{~T}$ scans from the same subjects were not different (paired t test $\mathrm{t}=0.18, p=0.9$ ) and were very highly correlated $(r=0.93, p<.001)$, indicating that there were no systematic differences in the tissue segmentation of 7T scans due to bias inhomogeneity (Iwabuchi et al., 2013). T1 weighted images were resliced (1 $\mathrm{mm}$ isotropic) and surface extraction and cortical parcellation for each individual structural image was carried out using Freesurfer version 5.1 (Fischl et al., 1999). The preprocessing followed the standard description available at (http://surfer.nmr.mgh.harvard.edu/). Image processing for morphometry was carried out blind to diagnosis. Cortical thickness was computed in accordance with the standard processing routines using Freesurfer with no control-point editing being required for this dataset (McCarthy et al., 2015). For this study, we employed Yeo's Functional Atlas (17networks) to parcellate the entire cortical surface (Yeo et al., 2011). Medial wall of the reconstructed hemispheres near the ventricles, proximal to the corpus callosum, was not included. The mean thickness of all vertices that were confined within the boundaries of the parcellated regions provided the network's thickness value, averaged across the 2 hemispheres. To compute the index for spatial coherence, we calculated the standard deviation of vertex wise thickness within each network, expressed as a ratio of the mean thickness (coefficient of variation of thickness, CVT). Higher CVT of a network in a subject indicates lower spatial coherence within the network for that individual. This computation is described in Figure 1. Thus, we obtained 17 mean thickness and CVT values for further analysis. A template identifying these networks is shown in Supplemental Figure 1.

\section{Statistical Analysis}

All statistical tests were carried out using SPSS version 25.0 (IBM Corp., Armonk, NY). T tests, Mann-Whitney $U$ tests for non-normal data and chi-square tests for proportions were used to compare clinical and demographic variables between patients and controls. Independent 2-tailed t-tests were used to compare CVT and mean cortical thickness of 17 networks between patients and healthy controls with False Discovery Rate (FDR) corrected $p<0.05$ considered as statistically significant for the 34 comparisons that were made. We then used nonparametric correlation (Kendall's rank 
correlation coefficient tau (Kendall, 1938)) to relate the TLI positive FTD scores to the CVT and mean thickness values of the networks with diagnostic differences, with FDR correction applied for the multiple correlations.

When undertaking a correlation with symptom severity, we assume that the scores vary continuously with brain structure. But structural changes may relate to the discrete presence and not vary continuously with severity. To ensure that our interpretations are not biased by this assumption, we divided the patient sample into binary categories based on the presence of positive FTD (pFTD+ vs pFTD-) defined as scores of $>0.25$ summed positive FTD score (disorganization), in line with the original work on TLI. The CVT and mean thickness values of the networks with diagnostic differences were directly compared between pFTD+ and pFTD- groups.

To test the specificity of our findings to positive FTD, we also repeated the above analyses with negative FTD scores. We also removed the variance in grey matter thickness and CVT explained by current antipsychotic defined daily dose (DDD), age, $I Q$, global functioning (GAF scores), and total intracranial volume and related the residuals to positive and negative FTD to establish specificity of the observed relationships.

\section{Results}

Demographic and clinical features of the sample are presented in Table 1, highlighting match for age, gender and parental socioeconomic status between the 2 groups.

\section{Diagnostic differences}

Network-based thickness differences between patients and healthy controls are shown in Table 2 (with descriptive labels as per Baker et al., 2014). The frontoparietal network and the midline default mode network showed the most significant reduction in cortical thickness (networks \#12 and \#16 of Yeo atlas) in patients when compared to controls. The cingulo-insular salience network and the frontoparietal networks (\#8 and \#12) had higher CVT in patients compared to controls, indicating spatial incoherence within these cognitive control networks in patients with schizophrenia.

\section{Relationship with positive FTD}

A higher CVT of the salience network (tau $=0.41 p=0.024)$ and lower mean thickness in frontoparietal network (tau $=-0.498, p=0.006$ ) predicted the severity of positive FTD (after FDR correction). CVT of the frontoparietal network (tau $=0.298, p=0.10$ ) and mean thickness of the default mode network (tau $=-0.355, p=0.05$ ) did not show $a$ significant relationship with the severity of positive FTD, even at the uncorrected level.

Residuals adjusted for the linear influence of antipsychotic dose, age, IQ, overall functioning, and total intracranial volume continued to demonstrate a significant relationship between higher CVT of the salience network (tau $=0.37 p=0.04$; Figure 2) 
and lower mean thickness in frontoparietal control network (tau $=-0.48, p=0.008$ ) with the severity of positive FTD. Positive FTD did not relate to the adjusted residuals of other structural measures involving the default mode and the language networks.

In direct group comparison, pFTD+ group showed significant reduction in mean thickness of the frontoparietal control network $(t=2.93, p=0.009)$ and increase in spatial incoherence indexed by CVT of the salience network $(t=-2.96, p=0.009)$, indicating that both the presence and the severity of positive FTD is influenced by these 2 networks.

\section{FTD and the structure of language networks}

We did not find significant correlations between the mean thickness and CVT of the 2 language networks (\#14 and 17 of Yeo atlas) that include Wernicke's and Broca's regions and positive FTD scores, even at an uncorrected level (absolute values of tau $=0.18$ to $0.30 ; p=0.06-0.31$ ). Nevertheless, $p F T D+$ group showed a significant reduction in mean thickness of the auditory network that included superior temporal cortex $(\# 14)(t$ $=3.68, p=0.002$ ) when compared to the pFTD- group, indicating that the presence of positive FTD, rather than its severity, is influenced by the structure of the language network comprising of superior temporal gyrus.

Furthermore, we did not find significant correlations between the thickness and CVT of the frontoparietal network, CVT of the salience network, the thickness of default network or the mean thickness and CVT of the 2 language networks (\#14 and 17) with negative FTD scores, even at an uncorrected level (absolute values of tau $=0.07-0.32 ; p=0.09$ 0.71 ). On binary analysis, $\mathrm{nFTD}+$ group showed a significant reduction in mean thickness of the network that included middle temporal gyrus $(\# 17)(t=2.3, p=0.034)$ when compared to the nFTD- group, but this did not survive FDR correction for the $t$ tests involving the language networks. Adjusting for the linear influence of antipsychotic dose, age, IQ, overall functioning, and total intracranial volume did not alter these results.

The above results are summarized in Figure 3 . The comparisons of pFTD + and pFTDgroups, nFTD+ and nFTD- groups, and the lack of relationship between network structure and suspected confounds (delusions, hallucinations, IQ and total symptom severity), the possible effect of varying network size are presented in the Supplement.

\section{Discussion}

To our knowledge, this is the first study investigating cortical thickness of functional networks in relation to FTD in schizophrenia. In this study, we have shown that (1) clinically stable and medicated individuals with schizophrenia exhibit reduced thickness of the frontoparietal and default mode networks, and spatial incoherence affecting the salience and the frontoparietal network (2) Patients with more severe burden of positive FTD had reduced frontoparietal network thickness and spatial coherence of the salience network (3) The presence of positive FTD, but not its severity, related to the reduced 
thickness of the auditory network comprising of the superior temporal cortex. Taken together, these results indicate that the severity of FTD is contingent upon the degree to which domain-general control aspects of information processing (i.e. frontoparietal and salience systems (Cole et al., 2014; Fedorenko et al., 2013)) are affected in schizophrenia, over and above the structural deficits in the language areas (i.e. temporal cortex).

While the reduced thickness of the frontoparietal and default mode regions has been reported consistently in many previous studies of schizophrenia (Ehrlich et al., 2012; Heinrichs et al., 2017; Park et al., 2018; Shafiei et al., 2019), the presence of spatial incoherence has not been investigated so far to our knowledge. The presence of higher than expected variation in the vertexwise thickness of large-scale cortical networks involved in information processing (salience and frontoparietal cognitive control) may indicate the possibility of a disturbance in coordinated structural maturation (AlexanderBloch et al., 2013b). A developmental lag in intracortical myelination or synaptic pruning (Fjell et al., 2015) of one region relative to the others within a network can result in such incoherence. Given the genetic control of intracortical myelination of during adolescence is closely related to the risk of schizophrenia (Whitaker et al., 2016), this possibility requires further investigation. It is also possible that the harmonious functional deployment of the network nodes do not occur as expected in patients, leading to a structural reconfiguration indicated by increased vertex-wise variance in thickness. This possibility has been raised previously in a study of spatial topography of functional connectivity in schizophrenia (Skudlarski et al., n.d.). While the results presented here cannot distinguish these two mechanisms, our results indicate that within-subject structural variability is an useful source of information to understand the elusive neural basis of complex symptoms such as formal thought disorder.

Our results partially confirm the long suspected role of language network in positive FTD, and add further clarity to the putative mechanistic basis of the observed disorganized thinking in schizophrenia. While structural changes involving both the cognitive control (frontoparietal and salience) and the language (auditory) network are seen in patients with positive FTD, the severity of the clinically expressed FTD relies on the degree to which the control systems are affected. In particular, both a reduction in the amount of grey matter tissue in the frontoparietal network and the variable distribution of grey matter within the salience network, appear to mediate the expressed severity of the disorganized thought in schizophrenia. This is consistent with the previously reported relationship between disorganisation and the disturbed functional relationships between the nodes of the salience network (ACC and insula)(Liddle et al., 1992), as well as a recent observation that the functional flexibility of the salience network predicts conceptual disorganisation but not the negative symptoms (Supekar et al., 2019). The notion of 'cognitive control systems' tuning the expression of a language system abnormality is in line with the current notions on cognitive control of language (Blank et al., 2014; Fedorenko and Varley, 2016), and consistent with the clinical observations that the severity of FTD increases when excessive cognitive demands (e.g. 
distraction, longer conversations) are placed on an individual with schizophrenia (Becker et al., 2012; Docherty, 2012).

In our previous study, we noted that a reduction in grey matter volume involving the insula, precuneus and lateral temporal regions in the presence of an increase in grey matter volume involving the cingulate and lateral prefrontal regions predicted higher burden of negative FTD, but not the positive FTD (Palaniyappan et al., 2015). Our current observations relate positive FTD to the salience (insula, ACC) and lateral frontoparietal as well as the auditory network (lateral temporal) structure; such a relationship was not seen for negative FTD. The lack of relationship between cortical thickness and negative FTD is in line with one previous report (Winkelbeiner et al., 2018), and indicate that maturational defects that affect morphometric properties other than thickness (e.g. surface area or gyrification (Palaniyappan and Liddle, 2012)) may be more critical for developing negative FTD. Our observed relationship between positive FTD and the salience and lateral frontoparietal network structure also resonates with the tendency for positive FTD severity to relate to the reduced regional blood flow in various nodes of the salience network (mid-cingulate and supplementary motor area) and frontoparietal regions (angular gyrus) reported by Stegmayer et al. (2017). Taken together, these results indicate that both forms of persistent FTD result from crossnetwork structural aberrations involving both the language-specific as well as cognitive control systems.

There are several limitations in our study. First, we had a limited sample size that precluded us from undertaking a mass univariate approach to the analysis. Nevertheless, it is important to note that we had sufficient power to reject the 2 primary null hypotheses (no patient vs. control differences and lack of structural correlates of positive FTD) with a low probability of false discovery. The possibility of type 2 error due to small sample cannot be fully dismissed for the null results relating to the language network and secondary analysis of the negative FTD scores. We urge caution when interpreting these negative results. Second, unlike Sans-Sansa et al. (2013), our patient sample was selected for its clinical stability but not for exhibiting FTD. While this may be a limitation, this enabled us to capture the milder but persistent aspects of FTD and thus provided a more representative sample when seeking morphological correlates of persistent as opposed to acute FTD. Third, we did not measure the subjective component of thought disorder that can be quantified using more recent instruments such as the Thought and Language Disorder (TALD) scale (Kircher et al., 2014). Nevertheless, most of the existing FTD-specific instruments consistently differentiate the positive and negative FTD dimensions, indicating that the biological mechanisms discussed here are likely to be valid irrespective of the specific instrument employed. We also did not see any observable positive FTD among healthy controls (See Supplement for a detailed discussion). TLI is an observer rated scale; there are likely advantages in attempting to find an entirely objective marker of thought, language and communication disruption and relate this to brain variables. We did not pursue any Natural Language Processing (NLP) approaches unlike in our prior work (Palaniyappan et al., 2019b), as 
our goal for this work was more modest, in pursuit of the anatomical substrate of clinically identifiable FTD.

In summary, we demonstrate that the cortical thickness of both cognitive control and language networks underlie the positive FTD in schizophrenia. The structural integrity of cognitive control networks is a critical determinant of the expressed severity of persistent FTD in schizophrenia.

\section{References}

Alexander-Bloch, A., Giedd, J.N., Bullmore, E., 2013a. Imaging structural co-variance between human brain regions. Nat. Rev. Neurosci. 14, 322-336. https://doi.org/10.1038/nrn3465

Alexander-Bloch, A., Raznahan, A., Bullmore, E., Giedd, J., 2013b. The Convergence of Maturational Change and Structural Covariance in Human Cortical Networks. J. Neurosci. 33, 2889-2899. https://doi.org/10.1523/JNEUROSCI.355412.2013

American Psychiatric Association, 1994. Diagnostic and statistical manual of mental disorders, 4th ed. Washington D.C.

Ammons, R.B., Ammons, C.H., 1962. The Quick Test (QT): Provisional manual. Psychol. Rep. 11, 111-161.

Annett, M., 1970. A classification of hand preference by association analysis. Br. J. Psychol. Lond. Engl. 1953 61, 303-321.

Baker, J.T., Holmes, A.J., Masters, G.A., Thomas Yeo, B.T., Krienen, F., Buckner, R.L., Öngür, D., 2014. Disruption of Cortical Association Networks in Schizophrenia and Psychotic Bipolar Disorder. JAMA Psychiatry 71, 109-118. https://doi.org/10.1001/jamapsychiatry.2013.3469

Bearden, C.E., Wu, K.N., Caplan, R., Cannon, T.D., 2011. Thought disorder and communication deviance as predictors of outcome in youth at clinical high risk for psychosis. J. Am. Acad. Child Adolesc. Psychiatry 50, 669-680. https://doi.org/10.1016/j.jaac.2011.03.021

Becker, T.M., Cicero, D.C., Cowan, N., Kerns, J.G., 2012. Cognitive control components and speech symptoms in people with schizophrenia. Psychiatry Res. 196, 2026. https://doi.org/10.1016/j.psychres.2011.10.003

Blank, I., Kanwisher, N., Fedorenko, E., 2014. A functional dissociation between language and multiple-demand systems revealed in patterns of BOLD signal fluctuations. J. Neurophysiol. 112, 1105-1118. https://doi.org/10.1152/jn.00884.2013

Bora, E., Yalincetin, B., Akdede, B.B., Alptekin, K., 2019. Neurocognitive and linguistic correlates of positive and negative formal thought disorder: A meta-analysis. Schizophr. Res. 209, 2-11. https://doi.org/10.1016/j.schres.2019.05.025

Cavelti, M., Homan, P., Vauth, R., 2016. The impact of thought disorder on therapeutic alliance and personal recovery in schizophrenia and schizoaffective disorder: An exploratory study. Psychiatry Res. 239, 92-98. https://doi.org/10.1016/j.psychres.2016.02.070 
Cavelti, M., Kircher, T., Nagels, A., Strik, W., Homan, P., 2018a. Is formal thought disorder in schizophrenia related to structural and functional aberrations in the language network? A systematic review of neuroimaging findings. Schizophr. Res. 199, 2-16. https://doi.org/10.1016/j.schres.2018.02.051

Cavelti, M., Winkelbeiner, S., Federspiel, A., Walther, S., Stegmayer, K., Giezendanner, S., Laimböck, K., Dierks, T., Strik, W., Horn, H., Homan, P., 2018b. Formal thought disorder is related to aberrations in language-related white matter tracts in patients with schizophrenia. Psychiatry Res. Neuroimaging 279, 4050. https://doi.org/10.1016/j.pscychresns.2018.05.011

Cohen, A.S., Le, T.P., Fedechko, T.L., Elvevåg, B., 2017. Can RDoC Help Find Order in Thought Disorder? Schizophr. Bull. 43, 503-508. https://doi.org/10.1093/schbul/sbx030

Cole, M.W., Repovs, G., Anticevic, A., 2014. The frontoparietal control system: A central role in mental health. Neurosci. Rev. J. Bringing Neurobiol. Neurol. Psychiatry 20, 652-664. https://doi.org/10.1177/1073858414525995

de Bruin, E.I., Verheij, F., Wiegman, T., Ferdinand, R.F., 2007. Assessment of formal thought disorder: The relation between the Kiddie Formal Thought Disorder Rating Scale and clinical judgment. Psychiatry Res. 149, 239-246. https://doi.org/10.1016/j.psychres.2006.01.018

Demjaha, A., Weinstein, S., Stahl, D., Day, F., Valmaggia, L., Rutigliano, G., De Micheli, A., Fusar-Poli, P., McGuire, P., 2017. Formal thought disorder in people at ultra-high risk of psychosis. BJPsych Open 3, 165-170. https://doi.org/10.1192/bjpo.bp.116.004408

DeVylder, J.E., Muchomba, F.M., Gill, K.E., Ben-David, S., Walder, D.J., Malaspina, D., Corcoran, C.M., 2014. Symptom trajectories and psychosis onset in a clinical high-risk cohort: the relevance of subthreshold thought disorder. Schizophr. Res. 159, 278-283. https://doi.org/10.1016/j.schres.2014.08.008

Docherty, N.M., 2012. On identifying the processes underlying schizophrenic speech disorder. Schizophr. Bull. 38, 1327-1335. https://doi.org/10.1093/schbul/sbr048

Ehrlich, S., Brauns, S., Yendiki, A., Ho, B.-C., Calhoun, V., Schulz, S.C., Gollub, R.L., Sponheim, S.R., 2012. Associations of Cortical Thickness and Cognition in Patients With Schizophrenia and Healthy Controls. Schizophr. Bull. 38, 10501062. https://doi.org/10.1093/schbul/sbr018

Fedorenko, E., Duncan, J., Kanwisher, N., 2013. Broad domain generality in focal regions of frontal and parietal cortex. Proc. Natl. Acad. Sci. U. S. A. 110, 16616-16621. https://doi.org/10.1073/pnas.1315235110

Fedorenko, E., Varley, R., 2016. Language and thought are not the same thing: evidence from neuroimaging and neurological patients. Ann. N. Y. Acad. Sci. 1369, 132-153. https://doi.org/10.1111/nyas.13046

Fischl, B., Sereno, M.I., Dale, A.M., 1999. Cortical Surface-Based Analysis: II: Inflation, Flattening, and a Surface-Based Coordinate System. NeuroImage 9, 195-207. https://doi.org/10.1006/nimg.1998.0396

Fjell, A.M., Grydeland, H., Krogsrud, S.K., Amlien, I., Rohani, D.A., Ferschmann, L., Storsve, A.B., Tamnes, C.K., Sala-Llonch, R., Due-Tønnessen, P., Bjørnerud, A., Sølsnes, A.E., Håberg, A.K., Skranes, J., Bartsch, H., Chen, C.-H., Thompson, 
W.K., Panizzon, M.S., Kremen, W.S., Dale, A.M., Walhovd, K.B., 2015. Development and aging of cortical thickness correspond to genetic organization patterns. Proc. Natl. Acad. Sci. U. S. A. 112, 15462-15467. https://doi.org/10.1073/pnas.1508831112

Gooding, D.C., Ott, S.L., Roberts, S.A., Erlenmeyer-Kimling, L., 2013. Thought disorder in mid-childhood as a predictor of adulthood diagnostic outcome: findings from the New York High-Risk Project. Psychol. Med. 43, 1003-1012. https://doi.org/10.1017/S0033291712001791

Guo, S., Palaniyappan, L., Liddle, P.F., Feng, J., 2016. Dynamic cerebral reorganization in the pathophysiology of schizophrenia: a MRI-derived cortical thickness study. Psychol. Med. 46, 2201-2214. https://doi.org/10.1017/S0033291716000994

Harrow, M., Marengo, J.T., 1986. Schizophrenic thought disorder at followup: its persistence and prognostic significance. Schizophr. Bull. 12, 373-393.

Heinrichs, R.W., Pinnock, F., Parlar, M., Hawco, C., Hanford, L., Hall, G.B., 2017. Cortical Thinning in Network-Associated Regions in Cognitively Normal and Below-Normal Range Schizophrenia. Schizophr. Res. Treat. 2017. https://doi.org/10.1155/2017/9760905

Iwabuchi, S., Liddle, P.F., Palaniyappan, L., 2013. Clinical utility of machine learning approaches in schizophrenia: Improving diagnostic confidence for translational neuroimaging. Front. Neuropsychiatr. Imaging Stimul. 4:, 95. https://doi.org/10.3389/fpsyt.2013.00095

Jerónimo, J., Queirós, T., Cheniaux, E., Telles-Correia, D., 2018. Formal Thought Disorders-Historical Roots. Front. Psychiatry 9. https://doi.org/10.3389/fpsyt.2018.00572

Kelly, C., Castellanos, F.X., 2014. Strengthening Connections: Functional Connectivity and Brain Plasticity. Neuropsychol. Rev. 24, 63-76. https://doi.org/10.1007/s11065-014-9252-y

Kendall, M.G., 1938. A NEW MEASURE OF RANK CORRELATION. Biometrika 30, 8193. https://doi.org/10.1093/biomet/30.1-2.81

Kircher, T., Bröhl, H., Meier, F., Engelen, J., 2018. Formal thought disorders: from phenomenology to neurobiology. Lancet Psychiatry 5, 515-526. https://doi.org/10.1016/S2215-0366(18)30059-2

Kircher, T., Krug, A., Stratmann, M., Ghazi, S., Schales, C., Frauenheim, M., Turner, L., Fährmann, P., Hornig, T., Katzev, M., Grosvald, M., Müller-Isberner, R., Nagels, A., 2014. A rating scale for the assessment of objective and subjective formal Thought and Language Disorder (TALD). Schizophr. Res. 160, 216-221. https://doi.org/10.1016/j.schres.2014.10.024

Kong, R., Li, J., Orban, C., Sabuncu, M.R., Liu, H., Schaefer, A., Sun, N., Zuo, X.-N., Holmes, A.J., Eickhoff, S.B., Yeo, B.T.T., 2019. Spatial Topography of Individual-Specific Cortical Networks Predicts Human Cognition, Personality, and Emotion. Cereb. Cortex 29, 2533-2551. https://doi.org/10.1093/cercor/bhy123

Kong, X., Wang, X., Huang, L., Pu, Y., Yang, Z., Dang, X., Zhen, Z., Liu, J., 2014. Measuring individual morphological relationship of cortical regions. J. 
Neurosci. Methods 237, 103-107.

https://doi.org/10.1016/j.jneumeth.2014.09.003

Leckman, J.F., Sholomskas, D., Thompson, D., Belanger, A., Weissman, M.M., 1982.

Best Estimate of Lifetime Psychiatric Diagnosis: A Methodological Study.

Arch Gen Psychiatry 39, 879-883.

https://doi.org/10.1001/archpsyc.1982.04290080001001

Li, M., Li, X., Das, T.K., Deng, W., Li, Y., Zhao, L., Ma, X., Wang, Y., Yu, H., Meng, Y., Wang, Q., Palaniyappan, L., Li, T., 2019. Prognostic Utility of Multivariate Morphometry in Schizophrenia. Front. Psychiatry 10.

https://doi.org/10.3389/fpsyt.2019.00245

Liddle, P.F., Friston, K.J., Frith, C.D., Hirsch, S.R., Jones, T., Frackowiak, R.S., 1992.

Patterns of cerebral blood flow in schizophrenia. Br. J. Psychiatry J. Ment. Sci. 160, 179-186.

Liddle, Peter F., Ngan, E.T.C., Caissie, S.L., Anderson, C.M., Bates, A.T., Quested, D., White, R., Weg, R., 2002. Thought and Language Index: an instrument for assessing thought and language in schizophrenia. Br. J. Psychiatry 181, 326330. https://doi.org/10.1192/bjp.181.4.326

Liddle, Peter F, Ngan, E.T.C., Duffield, G., Kho, K., Warren, A.J., 2002. Signs and Symptoms of Psychotic Illness (SSPI): a rating scale. Br. J. Psychiatry 180, 4550. https://doi.org/10.1192/bjp.180.1.45

McCarthy, C.S., Ramprashad, A., Thompson, C., Botti, J.-A., Coman, I.L., Kates, W.R., 2015. A comparison of FreeSurfer-generated data with and without manual intervention. Front. Neurosci. 9. https://doi.org/10.3389/fnins.2015.00379

Murray, A., 1943. Thematic apperception test. Harvard University Press, Cambridge, MA, US.

Palaniyappan, L., 2009. Neural correlates of formal thought disorder. Br. J. Psychiatry 195.

Palaniyappan, L., Das, T.K., Winmill, L., Hough, M., James, A., 2019a. Progressive postonset reorganisation of MRI-derived cortical thickness in adolescents with schizophrenia. Schizophr. Res. 208, 477-478.

https://doi.org/10.1016/j.schres.2019.01.041

Palaniyappan, L., Liddle, P.F., 2012. Differential effects of surface area, gyrification and cortical thickness on voxel based morphometric deficits in schizophrenia. NeuroImage 60, 693-699. https://doi.org/10.1016/j.neuroimage.2011.12.058

Palaniyappan, L., Mahmood, J., Balain, V., Mougin, O., Gowland, P.A., Liddle, P.F., 2015. Structural correlates of formal thought disorder in schizophrenia: An ultra-high field multivariate morphometry study. Schizophr. Res. 168, 305312. https://doi.org/10.1016/j.schres.2015.07.022

Palaniyappan, L., Mota, N.B., Oowise, S., Balain, V., Copelli, M., Ribeiro, S., Liddle, P.F., 2019b. Speech structure links the neural and socio-behavioural correlates of psychotic disorders. Prog. Neuropsychopharmacol. Biol. Psychiatry 88, 112120. https://doi.org/10.1016/j.pnpbp.2018.07.007

Panizzon, M.S., Fennema-Notestine, C., Eyler, L.T., Jernigan, T.L., Prom-Wormley, E., Neale, M., Jacobson, K., Lyons, M.J., Grant, M.D., Franz, C.E., Xian, H., Tsuang, M., Fischl, B., Seidman, L., Dale, A., Kremen, W.S., 2009. Distinct Genetic 
Influences on Cortical Surface Area and Cortical Thickness. Cereb Cortex 19, 2728-2735. https://doi.org/10.1093/cercor/bhp026

Park, M.T.M., Raznahan, A., Shaw, P., Gogtay, N., Lerch, J.P., Chakravarty, M.M., 2018. Neuroanatomical phenotypes in mental illness: identifying convergent and divergent cortical phenotypes across autism, ADHD and schizophrenia. J. Psychiatry Neurosci. JPN 43, 201-212. https://doi.org/10.1503/jpn.170094 Roche, E., Creed, L., MacMahon, D., Brennan, D., Clarke, M., 2015. The Epidemiology and Associated Phenomenology of Formal Thought Disorder: A Systematic Review. Schizophr. Bull. 41, 951-962. https://doi.org/10.1093/schbul/sbu129

Roche, E., Segurado, R., Renwick, L., McClenaghan, A., Sexton, S., Frawley, T., Chan, C.K., Bonar, M., Clarke, M., 2016. Language disturbance and functioning in first episode psychosis. Psychiatry Res. 235, 29-37.

https://doi.org/10.1016/j.psychres.2015.12.008

Rose, D., Pevalin, D.J., 2003. A Researcher's Guide to the National Statistics Socioeconomic Classification. Sage Publications, London.

Sans-Sansa, B., McKenna, P.J., Canales-Rodríguez, E.J., Ortiz-Gil, J., López-Araquistain, L., Sarró, S., Dueñas, R.M., Blanch, J., Salvador, R., Pomarol-Clotet, E., 2013. Association of formal thought disorder in schizophrenia with structural brain abnormalities in language-related cortical regions. Schizophr. Res. 146, 308313. https://doi.org/10.1016/j.schres.2013.02.032

Shafiei, G., Markello, R.D., Makowski, C., Talpalaru, A., Kirschner, M., Devenyi, G.A., Guma, E., Hagmann, P., Cashman, N.R., Lepage, M., Chakravarty, M.M., Dagher, A., Mišić, B., 2019. Spatial patterning of tissue volume loss in schizophrenia reflects brain network architecture. Biol. Psychiatry.

https://doi.org/10.1016/j.biopsych.2019.09.031

Shin, J., French, L., Xu, T., Leonard, G., Perron, M., Pike, G.B., Richer, L., Veillette, S., Pausova, Z., Paus, T., 2018. Cell-Specific Gene-Expression Profiles and Cortical Thickness in the Human Brain. Cereb. Cortex 28, 3267-3277. https://doi.org/10.1093/cercor/bhx197

Skudlarski, P., Jagannathan, K., Anderson, K., Stevens, M.C., Calhoun, V.D., Skudlarska, B.A., Pearlson, G., n.d. Brain Connectivity Is Not Only Lower but Different in Schizophrenia: A Combined Anatomical and Functional Approach. Biol. Psychiatry In Press, Corrected Proof. https://doi.org/10.1016/j.biopsych.2010.03.035

Sommer, I.E., Derwort, A.M.C., Daalman, K., de Weijer, A.D., Liddle, P.F., Boks, M.P.M., 2010. Formal thought disorder in non-clinical individuals with auditory verbal hallucinations. Schizophr. Res. 118, 140-145. https://doi.org/10.1016/j.schres.2010.01.024

Sousa, P. de, Sellwood, W., Griffiths, M., Bentall, R.P., 2019. Disorganisation, thought disorder and socio-cognitive functioning in schizophrenia spectrum disorders. Br. J. Psychiatry 214, 103-112. https://doi.org/10.1192/bjp.2018.160

Stegmayer, K., Stettler, M., Strik, W., Federspiel, A., Wiest, R., Bohlhalter, S., Walther, S., 2017. Resting state perfusion in the language network is linked to formal 
thought disorder and poor functional outcome in schizophrenia. Acta Psychiatr. Scand. 136, 506-516. https://doi.org/10.1111/acps.12790 Storsve, A.B., Fjell, A.M., Tamnes, C.K., Westlye, L.T., Overbye, K., Aasland, H.W., Walhovd, K.B., 2014. Differential Longitudinal Changes in Cortical Thickness, Surface Area and Volume across the Adult Life Span: Regions of Accelerating and Decelerating Change. J. Neurosci. 34, 8488-8498. https://doi.org/10.1523/JNEUROSCI.0391-14.2014

Sumner, P.J., Bell, I.H., Rossell, S.L., 2018a. A systematic review of the structural neuroimaging correlates of thought disorder. Neurosci. Biobehav. Rev. 84, 299-315. https://doi.org/10.1016/j.neubiorev.2017.08.017

Sumner, P.J., Bell, I.H., Rossell, S.L., 2018b. A systematic review of task-based functional neuroimaging studies investigating language, semantic and executive processes in thought disorder. Neurosci. Biobehav. Rev. 94, 59-75. https://doi.org/10.1016/j.neubiorev.2018.08.005

Supekar, K., Cai, W., Krishnadas, R., Palaniyappan, L., Menon, V., 2019. Dysregulated Brain Dynamics in a Triple-Network Saliency Model of Schizophrenia and Its Relation to Psychosis. Biol. Psychiatry 85, 60-69. https://doi.org/10.1016/j.biopsych.2018.07.020

Tan, E.J., Rossell, S.L., 2017. Formal thought disorder and neurocognition in schizophrenia: The question of individual mechanisms. Schizophr. Res. 190, 189-190. https://doi.org/10.1016/j.schres.2017.03.039

Tan, E.J., Thomas, N., Rossell, S.L., 2014. Speech disturbances and quality of life in schizophrenia: differential impacts on functioning and life satisfaction. Compr. Psychiatry 55, 693-698. https://doi.org/10.1016/j.comppsych.2013.10.016

Ulas, H., Akdede, B.B., Ozbay, D., Alptekin, K., 2008. Effect of thought disorders on quality of life in patients with schizophrenia. Prog. Neuropsychopharmacol. Biol. Psychiatry 32, 332-335. https://doi.org/10.1016/j.pnpbp.2007.08.033 van Erp, T.G.M., Walton, E., Hibar, D.P., Schmaal, L., Jiang, W., Glahn, D.C., Pearlson, G.D., Yao, N., Fukunaga, M., Hashimoto, R., Okada, N., Yamamori, H., Bustillo, J.R., Clark, V.P., Agartz, I., Mueller, B.A., Cahn, W., de Zwarte, S.M.C., Hulshoff Pol, H.E., Kahn, R.S., Ophoff, R.A., van Haren, N.E.M., Andreassen, O.A., Dale, A.M., Doan, N.T., Gurholt, T.P., Hartberg, C.B., Haukvik, U.K., Jørgensen, K.N., Lagerberg, T.V., Melle, I., Westlye, L.T., Gruber, O., Kraemer, B., Richter, A., Zilles, D., Calhoun, V.D., Crespo-Facorro, B., Roiz-Santiañez, R., TordesillasGutiérrez, D., Loughland, C., Carr, V.J., Catts, S., Cropley, V.L., Fullerton, J.M., Green, M.J., Henskens, F.A., Jablensky, A., Lenroot, R.K., Mowry, B.J., Michie, P.T., Pantelis, C., Quidé, Y., Schall, U., Scott, R.J., Cairns, M.J., Seal, M., Tooney, P.A., Rasser, P.E., Cooper, G., Shannon Weickert, C., Weickert, T.W., Morris, D.W., Hong, E., Kochunov, P., Beard, L.M., Gur, R.E., Gur, R.C., Satterthwaite, T.D., Wolf, D.H., Belger, A., Brown, G.G., Ford, J.M., Macciardi, F., Mathalon, D.H., O'Leary, D.S., Potkin, S.G., Preda, A., Voyvodic, J., Lim, K.O., McEwen, S., Yang, F., Tan, Y., Tan, S., Wang, Z., Fan, F., Chen, J., Xiang, H., Tang, S., Guo, H., Wan, P., Wei, D., Bockholt, H.J., Ehrlich, S., Wolthusen, R.P.F., King, M.D., Shoemaker, J.M., Sponheim, S.R., De Haan, L., Koenders, L., Machielsen, M.W., van Amelsvoort, T., Veltman, D.J., Assogna, F., Banaj, N., de Rossi, P., Iorio, M., 
Piras, F., Spalletta, G., McKenna, P.J., Pomarol-Clotet, E., Salvador, R., Corvin, A., Donohoe, G., Kelly, S., Whelan, C.D., Dickie, E.W., Rotenberg, D., Voineskos, A.N., Ciufolini, S., Radua, J., Dazzan, P., Murray, R., Reis Marques, T., Simmons, A., Borgwardt, S., Egloff, L., Harrisberger, F., Riecher-Rössler, A., Smieskova, R., Alpert, K.I., Wang, L., Jönsson, E.G., Koops, S., Sommer, I.E.C., Bertolino, A., Bonvino, A., Di Giorgio, A., Neilson, E., Mayer, A.R., Stephen, J.M., Kwon, J.S., Yun, J.-Y., Cannon, D.M., McDonald, C., Lebedeva, I., Tomyshev, A.S., Akhadov, T., Kaleda, V., Fatouros-Bergman, H., Flyckt, L., Karolinska Schizophrenia Project, Busatto, G.F., Rosa, P.G.P., Serpa, M.H., Zanetti, M.V., Hoschl, C., Skoch, A., Spaniel, F., Tomecek, D., Hagenaars, S.P., McIntosh, A.M., Whalley, H.C., Lawrie, S.M., Knöchel, C., Oertel-Knöchel, V., Stäblein, M., Howells, F.M., Stein, D.J., Temmingh, H.S., Uhlmann, A., Lopez-Jaramillo, C., Dima, D., McMahon, A., Faskowitz, J.I., Gutman, B.A., Jahanshad, N., Thompson, P.M., Turner, J.A., 2018. Cortical Brain Abnormalities in 4474 Individuals With Schizophrenia and 5098 Control Subjects via the Enhancing Neuro Imaging Genetics Through Meta Analysis (ENIGMA) Consortium. Biol. Psychiatry 84, 644-654. https://doi.org/10.1016/j.biopsych.2018.04.023

Wensing, T., Cieslik, E.C., Müller, V.I., Hoffstaedter, F., Eickhoff, S.B., Nickl-Jockschat, T., 2017. Neural correlates of formal thought disorder: An activation likelihood estimation meta-analysis. Hum. Brain Mapp. 38, 4946-4965. https://doi.org/10.1002/hbm.23706

Whitaker, K.J., Vértes, P.E., Romero-Garcia, R., Váša, F., Moutoussis, M., Prabhu, G., Weiskopf, N., Callaghan, M.F., Wagstyl, K., Rittman, T., Tait, R., Ooi, C., Suckling, J., Inkster, B., Fonagy, P., Dolan, R.J., Jones, P.B., Goodyer, I.M., Consortium, the N., Bullmore, E.T., Goodyer, I., Bullmore, E., Dolan, R., Fonagy, P., Jones, P., Fletcher, P., Suckling, J., Weiskopf, N., Fearon, P., Inkster, B., Prabhu, G., Bernal-Casas, D., Eldar, E., Ganguly, T., Hauser, T., Ioannidis, K., Lewis, G., Mita, A., Moutoussis, M., Neufeld, S., Polek-MacDaeid, E., RomeroGarcia, R., Clair, M.S., Tait, R., Toseeb, U., Harmelen, A.-L. van, Vértes, P., Whitaker, K., Will, G.-J., Ziegler, G., Zimbron, J., Haarsma, J., Davies, S., Griffin, J., Hart, M., Váša, F., Wagstyl, K., Ooi, C., Widmer, B., Alrumaithi, A., Birt, S., Cleridou, K., Dadabhoy, H., Firkins, A., Granville, S., Harding, E., Hopkins, A., Isaacs, D., King, J., Knight, C., Kokorikou, D., Maurice, C., McIntosh, C., Memarzia, J., Mills, H., O’Donnell, C., Pantaleone, S., Scott, J., Stribling, A., Bhatti, J., Hubbard, N., Ilicheva, N., Kentell, M., Wallis, B., Villis, L., 2016. Adolescence is associated with genomically patterned consolidation of the hubs of the human brain connectome. Proc. Natl. Acad. Sci. 201601745. https://doi.org/10.1073/pnas.1601745113

WHO Collaborating Centre for Drug Statistics and Methodology, 2003. Guidelines for ATC Classification and DDD Assignment.

Wilcox, J., Briones, D., Quadri, S., Tsuang, M., 2014. Prognostic implications of paranoia and thought disorder in new onset psychosis. Compr. Psychiatry 55, 813-817. https://doi.org/10.1016/j.comppsych.2013.12.010

Winkelbeiner, S., Cavelti, M., Federspiel, A., Kunzelmann, K., Dierks, T., Strik, W., Horn, H., Homan, P., 2018. Decreased blood flow in the right insula and middle temporal gyrus predicts negative formal thought disorder in 
schizophrenia. Schizophr. Res. 201, 432-434.

https://doi.org/10.1016/j.schres.2018.06.009

Yeo, B.T., Krienen, F.M., Sepulcre, J., Sabuncu, M.R., Lashkari, D., Hollinshead, M., Roffman, J.L., Smoller, J.W., Zollei, L., Polimeni, J.R., Fischl, B., Liu, H., Buckner, R.L., 2011. The organization of the human cerebral cortex estimated by intrinsic functional connectivity. J. Neurophysiol. 106, 1125-1165.

https://doi.org/10.1152/jn.00338.2011

Acknowledgements: We are grateful to all the study participants and their families. We acknowledge the staff at the Early Intervention in Psychosis programme, Nottingham between 2010-2012. We also thank Dr. Vijender Balain (VB) who assisted in recruitment and clinical data collection and Dr. Jenaid Mahmood (JM) who derived the TLI scores. 
Table 1: Clinical and demographic features

\begin{tabular}{|c|c|c|c|}
\hline Features & $\begin{array}{l}\text { Patients (N=19) } \\
\text { Mean (SD) }\end{array}$ & $\begin{array}{l}\text { Controls (N=20) } \\
\text { Mean (SD) }\end{array}$ & Statistic \\
\hline Age & $33.2(9.8)$ & $32(8.2)$ & $\mathrm{t}=0.44$ \\
\hline DDD of antipsychotics & $0.8(0.7)$ & - & \\
\hline GAF score & $47.3(10.7)$ & $88.1(7.4)$ & $t=-13.9^{*}$ \\
\hline Gender (male/female) & $14 / 5$ & $15 / 5$ & $x^{2}=0.93$ \\
\hline Handedness (right/left) & $17 / 2$ & $18 / 2$ & $x^{2}=0.45$ \\
\hline Illness duration (years) & $7.7(8.3)$ & - & - \\
\hline $\begin{array}{l}\text { Intracranial Volume } \\
\text { (mls) }\end{array}$ & $1558.6(169.1)$ & 1593.3(146.8) & $t=-0.68$ \\
\hline Parental NS-SEC & $2.6(1.7)$ & $2.5(1.6)$ & $z=0.16$ \\
\hline $\begin{array}{l}\text { Quick Test (Premorbid } \\
\text { IQ) }\end{array}$ & $94.4(12.3)$ & $105.9(11.6)$ & $t=3.0^{*}$ \\
\hline SSPI Disorganisation & $0.2(0.7)$ & $0.1(0.3)$ & $Z=3.0^{*}$ \\
\hline $\begin{array}{l}\text { SSPI Psychomotor } \\
\text { Poverty }\end{array}$ & $2.3(3.7)$ & $0(0)$ & $Z=2.9^{*}$ \\
\hline SSPI Reality distortion & $2.4(2.9)$ & $0(0)$ & $Z=3.9^{*}$ \\
\hline SSPI total score & 11.1(10) & $0.6(0.8)$ & $z=5.0^{*}$ \\
\hline $\begin{array}{l}\text { TLI Disorganised } \\
\text { thinking } \\
\text { (Positive FTD) }\end{array}$ & $0.556(0.67)$ & $0(0)$ & $z=4.31^{* a}$ \\
\hline $\begin{array}{l}\text { TLI Impoverished } \\
\text { thinking } \\
\text { (Negative FTD) }\end{array}$ & $0.486(0.89)$ & $0.042(0.10)$ & $z=2.16^{\star a}$ \\
\hline TLI positive FTD (+/-) & $10 / 9$ & - & - \\
\hline TLI negative FTD (+/-) & $8 / 11$ & - & - \\
\hline
\end{tabular}

SD: standard deviation. DDD: Defined Daily Dose. GAF: Global Assessment of Functioning. IQ: Intelligence Quotient NS-SEC: National Statistics Socio-economic Classification. SSPI: Signs and Symptoms of Psychotic Illness. TLI: Thought and Language Index a2 patients and 1 control excluded for missing values due to poor quality of audio transcripts * Significantly different between the two groups at $p<0.05$. 
Table 2: Group differences in mean thickness and spatial coherence

\begin{tabular}{|c|c|c|c|c|c|}
\hline \multirow{2}{*}{$\begin{array}{l}\text { Yeo } 17 \text { Network } \\
\text { Description }\end{array}$} & \multirow[t]{2}{*}{ Primary regions included } & \multicolumn{2}{|c|}{ Mean Thickness } & \multicolumn{2}{|c|}{ CV Thickness } \\
\hline & & $\mathbf{t}$ & $\mathbf{p}$ & $\mathbf{t}$ & p \\
\hline Visual peripheral (\#1) & striate/extra-striate & 1.46 & 0.153 & -1.22 & 0.231 \\
\hline Visual central (\#2) & striate/extra-striate & 0.78 & 0.442 & -0.95 & 0.349 \\
\hline Somato-motor A (\#3) & central sulcus and secondary somatosensory & 1.35 & 0.184 & -0.40 & 0.694 \\
\hline Somato-motor B (\#4) & $\begin{array}{l}\text { posterior insula, auditory, central sulcus and secondary } \\
\text { somatosensory }\end{array}$ & 1.67 & 0.103 & -1.05 & 0.301 \\
\hline Dorsal Attention A (\#5) & $\begin{array}{l}\text { temporo-occipital, superior parietal and inferior parieto- } \\
\text { occipital }\end{array}$ & 2.42 & 0.020 & -1.79 & 0.081 \\
\hline Dorsal Attention B (\#6) & $\begin{array}{l}\text { frontal eye fields, precentral and postcentral, posterior } \\
\text { temporal }\end{array}$ & 1.70 & 0.098 & -1.38 & 0.175 \\
\hline Ventral Attention (\#7) & $\begin{array}{l}\text { anterior mid-insula, parietal operculum, medial parietal, } \\
\text { medial frontal, precentral and posterior temporal }\end{array}$ & 1.95 & 0.059 & -1.93 & 0.062 \\
\hline Salience (\#8) & $\begin{array}{l}\text { anterior insula, dorsal anterior cingulate, inferior parietal, } \\
\text { anterior lateral prefrontal }\end{array}$ & 2.73 & 0.010 & -3.13 & 0.003 \\
\hline Limbic A (\#9) & temporal pole & 2.11 & 0.042 & -0.65 & 0.517 \\
\hline Limbic B (\#10) & orbitorfrontal & 2.25 & 0.031 & -2.85 & 0.007 \\
\hline Control C (\#11) & dorsal precuneus, anterior cingulate & 2.08 & 0.044 & -1.05 & 0.299 \\
\hline Control A (\#12) & intraparietal, dorsolateral prefrontal, middle temporal & 2.98 & 0.005 & -3.14 & 0.003 \\
\hline Control B (\#13) & posterolateral prefrontal, inferior parietal & 2.15 & 0.039 & -1.99 & 0.054 \\
\hline Auditory (\#14) & superior temporal cortex & 1.52 & 0.138 & -1.29 & 0.205 \\
\hline Default C (\#15) & parahippocampal, retosplenial & 2.68 & 0.011 & -1.15 & 0.257 \\
\hline Default A (\#16) & medial prefrontal, precuneus, angular gyrus, orbitofrontal & 3.10 & 0.004 & -2.40 & 0.021 \\
\hline Default B(\#17) & inferior frontal, middle temporal and supramarginal & 1.84 & 0.073 & -1.50 & 0.141 \\
\hline
\end{tabular}

The naming convention follows Baker (2014). 
Figure 1: Estimating thickness-based spatial coherence within a functional network

I. For each vertex on grey-white boundary, the tangential distance to pial boundary provides a vertex-specific thickness measure, extracted using Freesurfer-based surface reconstruction. II. Using Yeo's 17 functional networks, the anatomical boundaries are defined for cortical networks. For any given network (Salience Network in this example), included regions are spatially distributed, with thickness varying across the vertices. III. Vertices that make up each network show variable thickness, that can be averaged to obtain mean thickness of the functional network, while standard deviation across the vertices provides the measure of variability. Disruptions in the coordinated maturation and/or functional co-activation within these networks may result in increased variability in thickness across the network IV. Hypothetical vertexwise thickness values plotted in a spatial continuum for 4 subjects. Subject $A$ shows moderate degree of variability with average mean thickness; Subject B shows low variability as well as low mean thickness; Subject $C$ shows high degree of variability with high mean thickness; Subject D shows low variability but high mean thickness. V. As variability scales with mean values (Taylor's law), the spatial coherence within a network is best captured by the coefficient of variation $(\mathrm{CV}=$ mean/standard deviation).

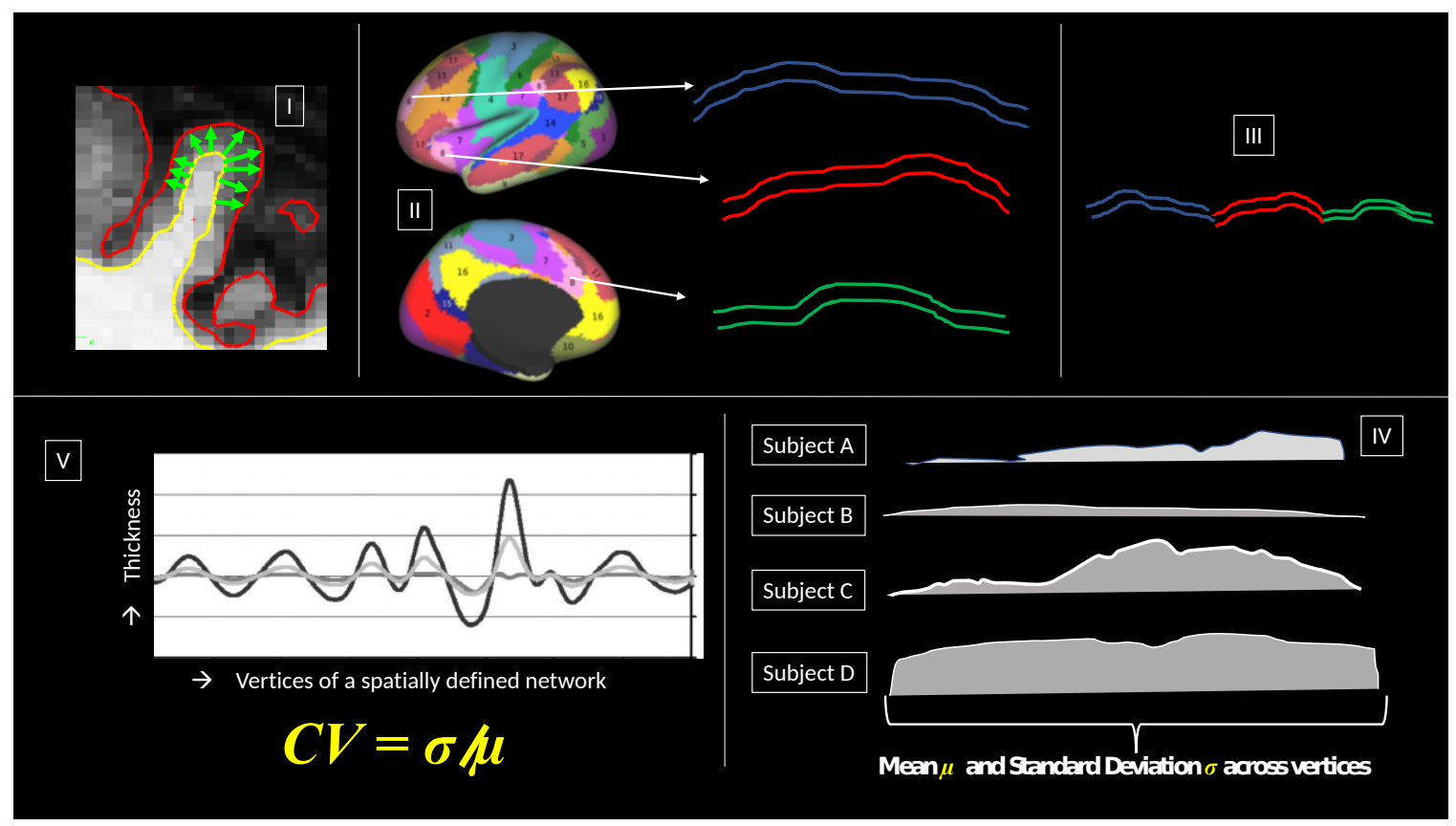


Figure 2: Relationship between spatial incoherence of the Salience Network and positive formal thought disorder

The residuals linearly adjusted for age, gender, intracranial volume, IQ, global functioning and antipsychotic dose are plotted on y-axis, and summed scores of positive formal thought disorder on the $x$-axis. Note that the scatter-plot depicts the linear relationship, while non-parametric correlations were used in the statistical analysis. CVT: Coefficient of Variation of Thickness; FTD: Formal Thought disorder; TLI: Thought \& Language Index.

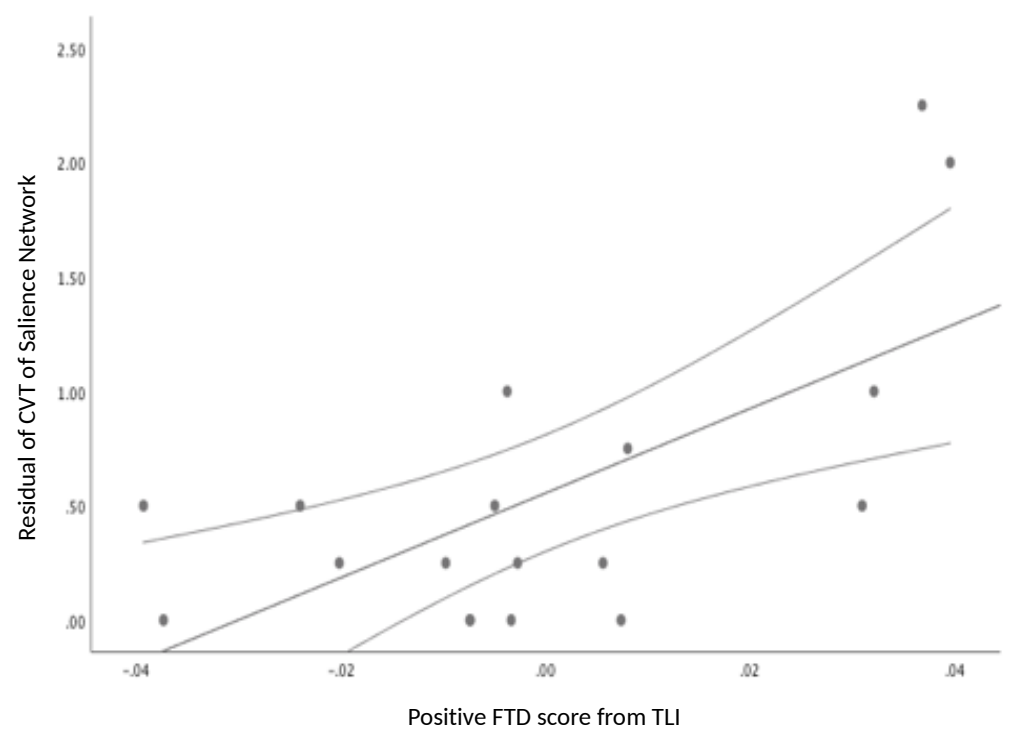


Figure 3: Network-based morphometric changes observed in relation to positive formal thought disorder

The top panel (warm colour) depicts the salience and the frontoparietal networks (Network \#8 and \#12 of Yeo 17 parcellation) associated with the categorical presence of positive FTD (pFTD+ vs pFTD- contrast) as well as demonstrating a relationship with the severity of positive FTD. The bottom panel (cool colour) depicts the language network (Network \#14 of Yeo 17 parcellation) associated only with the categorical presence of positive FTD (pFTD+ vs pFTD- contrast). FTD: Formal Thought disorder. Images derived using MRICron from ch2better T1 template; overlays produced from Yeo 17-network volume on the FSL MNI152 1mm Freesurfer conformed liberal mask. Networks not relevant to current results are whitened out.

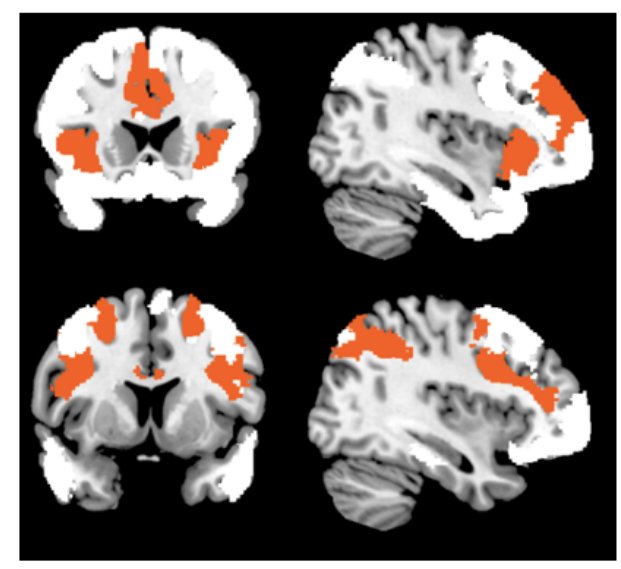

\section{Salience and frontoparietal control networks: Associated with the emergence as well as severity of positive FTD}

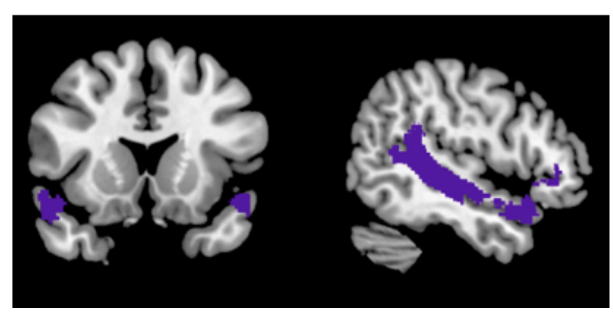

Superior and middle temporal language network: Associated with the emergence of positive FTD 


\section{Supplemental Information}

\section{TLI Scoring}

We used the same scores generated by a single trained rater as reported in our previous work (Palaniyappan et al., 2015)). Speech samples were audio recorded by two research psychiatrists (LP and VB) and transcribed and scored by a single rater (JM) blind to the diagnostic status, symptom burden of the subjects and neuroimaging findings. JM did not have any direct contact with the study participants, thus had no knowledge of their educational background as well. JM was trained using the TLI data from 70 subjects (with 3 speech samples from each subject) collected from a nonoverlapping sample from a different study (Palaniyappan et al., 2019b). During the training phase, several meetings were organized among the authors to develop consensus on how to interpret and score FTD using previously collected speech samples. Further, we used the examples from the original author (PFL) for reference. LP independently crosschecked all scores in accordance with the descriptive guidance provided by PFL.

\section{Lack of positive FTD in healthy controls}

To our knowledge, one prior study using the same TLI assessment in healthy controls, noted a low level $(n=50$, mean $(S D)=0.82(0.84))$ of positive FTD in healthy controls (Sommer et al., 2010). The sample of healthy controls in Sommer et al. was older in age $($ mean $(S D)=44(14)$ years $)$, predominantly female $(70 \%)$, with $16 \%$ having a lifetime history of depression. In addition, the healthy controls of Sommer et al. study comprised of individuals recruited through a website advertised to identify voice-hearers, but grouped as healthy controls when the ratings for voice-hearing items in a self-rated scale was zero. In our sample, we excluded healthy controls with a personal lifetime history of any psychiatric disorder or a family history of suspected psychosis, thus greatly reducing the likelihood of observing positive FTD in our sample. In this context, we urge caution in generalising the zero scores for positive FTD observed in our healthy control group, especially given the prior literature indicating notable positive FTD features in otherwise healthy individuals using multiple measurement approaches (Kircher et al., 2014).

\section{Exploring the effect of further confounders}

We compared the clinical features of pFTD+/- groups and nFTD+/- groups (see ST1 and ST2 below). These subgroups did not differ in terms of illness duration, SSPI symptom dimensions, medication dose, age, gender, handedness and GAF scores. Patients in pFTD+ group had lower Quick IQ score than the pFTD- groups. Patients in nFTD+ group had higher overall symptom burden (SSPI total) than the nFTD- groups.

We did not find any association between individual SSPI severity score of delusions, hallucinations or the summed scores of Reality Distortion, total SSPI scores, as well as Quick IQ score, and any of the network measures that related to the FTD scores of 
interest (See ST3 below). These results increase our confidence in the specificity of the reported relationships between network-based morphometry and FTD.

\section{The effect of the varying sizes of Yeo 17 networks on the reported results}

Networks with larger surface area may have more coefficient of variation (CV) in thickness, given that there are more datapoints to estimate the variance, as well as the mean values. We examined this issue by studying the linear relationship between area (representing the size) and mean thickness as well as CV of the networks across the 17 networks in each subject. The average of the correlation coefficients was not significantly different from null for both area-CV $(r=-0.288, p=0.26)$ and area-mean thickness relationships $(r=-0.248 p=0.34)$. We further examined if inter-individual variation in the area of the 4 key networks (\#8, \#12, \#14, \#16, identified to be clinically relevant in our study) explained the inter-individual in $\mathrm{CV}$ and mean thickness, after adjusting for the confounding effect of diagnosis, age and intracranial volume. We did not observe any significant relationships between network area and mean thickness $(|r|=0.06-0.3$, all $p>0.05)$. The lack of a significant relationship between area measure and mean and CV of thickness indicates that the intra- or inter-individual variations in the size of the networks do not explain the differences in mean or CV of thickness reported in the present study. 
Table S1: Comparison of pFTD+ and pFTD- patient groups

\begin{tabular}{llll}
\hline Features & $\begin{array}{l}\text { pFTD+ Patients } \\
(\mathbf{N}=10) \\
\text { Mean (SD) }\end{array}$ & $\begin{array}{l}\text { pFTD- patients (N=9) } \\
\text { Mean (SD) }\end{array}$ & Statistic \\
\hline Age & $31.8(11.2)$ & $34.9(8.4)$ & $\mathrm{t}=-0.67$ \\
DDD of antipsychotics & $0.62(0.58)$ & $1.03(0.69)$ & $\mathrm{z}=-0.74$ \\
GAF score & $44.5(12.1)$ & $50.3(8.5)$ & $\mathrm{t}=-1.2$ \\
\hline Gender (male/female) & $8 / 2$ & $6 / 3$ & $\mathrm{X}^{2}=0.43$ \\
Handedness (right/left) & $10 / 0$ & $7 / 2$ & - \\
IIIness duration (years) & $7.5(9.38)$ & $6.29(5.96)$ & $\mathrm{z}=0.0$ \\
Quick Test (Premorbid & $86.7(10.7)$ & $102.8(7.4)$ & $\mathrm{z}=-2.9^{*}$ \\
IQ) & $1.6(1.90)$ & $0.67(0.87)$ & $\mathrm{z}=1.04$ \\
SSPI Disorganisation & $2.60(4.2)$ & $1.78(3.3)$ & $\mathrm{z}=0.33$ \\
SSPI Psychomotor & & $1.78(2.5)$ & $\mathrm{z}=-0.72$ \\
$\begin{array}{l}\text { Poverty } \\
\text { SSPI Reality distortion }\end{array}$ & $2.90(3.1)$ & $4.22(6.06)$ & $\mathrm{z}=1.72$ \\
SSPI total score & $7.1(5.65)$ & $0.11(0.13)$ & $\mathrm{z}=3.65^{*}$ \\
$\begin{array}{l}\text { TLI Disorganised } \\
\text { thinking }\end{array}$ & $1.00(0.67)$ & & $\mathrm{z}=1.31$ \\
(Positive FTD) & & $0.17(0.25)$ & \\
$\begin{array}{l}\text { TLI Impoverished } \\
\text { thinking } \\
\text { (Negative FTD) }\end{array}$ & $0.81(1.18)$ & & \\
\hline
\end{tabular}

SD: standard deviation. DDD: Defined Daily Dose. GAF: Global Assessment of Functioning. IQ: Intelligence Quotient SSPI: Signs and Symptoms of Psychotic Illness. TLI: Thought and Language Index. FTD: Formal Thought Disorder * Significantly different between the two groups at $p<0.05$ ( $z$ values reported for non-parametric rank-tests). 
Table S2: Comparison of nFTD+ and nFTD- patient groups

\begin{tabular}{llll}
\hline Features & $\begin{array}{l}\text { nFTD+ Patients } \\
(\mathbf{N}=8) \\
\text { Mean (SD) }\end{array}$ & $\begin{array}{l}\text { nFTD- patients (N=11) } \\
\text { Mean (SD) }\end{array}$ & Statistic \\
\hline Age & $30.12(9.4)$ & $35.55(9.9)$ & $\mathrm{t}=-1.2$ \\
DDD of antipsychotics & $0.91(0.63)$ & $0.75(0.69)$ & $\mathrm{z}=-0.83$ \\
GAF score & $45.87(13.8)$ & $48.27(8.4)$ & $\mathrm{t}=-0.47$ \\
\hline Gender (male/female) & $5 / 3$ & $9 / 2$ & $\mathrm{X}^{2}=0.89$ \\
Handedness (right/left) & $1 / 7$ & $1 / 10$ & $\mathrm{X}^{2}=0.06$ \\
IIIness duration (years) & $6.0(7.3)$ & $7.7(8.7)$ & $\mathrm{z}=-0.78$ \\
Quick Test (Premorbid & $90.63(11.4)$ & $97.1(12.7)$ & $\mathrm{z}=-1.42$ \\
IQ) & & $0.73(1.0)$ & $\mathrm{z}=1.14$ \\
SSPI Disorganisation & $1.75(2.0)$ & $1.09(2.4)$ & $\mathrm{z}=1.77$ \\
SSPI Psychomotor & $3.75(4.8)$ & $1.36(1.9)$ & $\mathrm{Z}=1.59$ \\
$\begin{array}{l}\text { Poverty } \\
\text { SSPI Reality distortion }\end{array}$ & $3.75(3.5)$ & $3.18(3.49)$ & $\mathrm{z}=2.20^{*}$ \\
$\begin{array}{l}\text { SSPI total score } \\
\text { TLI Disorganised }\end{array}$ & $9.25(6.84)$ & $0.5(0.62)$ & $\mathrm{z}=0.55$ \\
thinking & $0.64(0.75)$ & & $\mathrm{z}=3.84^{*}$ \\
(Positive FTD) & & $0.02(0.08)$ & \\
$\begin{array}{l}\text { TLI Impoverished } \\
\text { thinking }\end{array}$ & $1.2(1.1)$ & & \\
(Negative FTD) & & & \\
\hline
\end{tabular}

SD: standard deviation. DDD: Defined Daily Dose. GAF: Global Assessment of Functioning. IQ: Intelligence Quotient SSPI: Signs and Symptoms of Psychotic Illness. TLI: Thought and Language Index. FTD: Formal Thought Disorder * Significantly different between the two groups at $p<0.05$ ( $z$ values reported for non-parametric rank-tests). 
Table S3: Relationship between network structure and suspected confounding factors (Kendall's tau coefficients)

\begin{tabular}{l|l|l|l|l|} 
& $\begin{array}{l}\text { CVT } \\
\text { Network\#8 }\end{array}$ & $\begin{array}{l}\text { Mean } \\
\text { Thickness } \\
\text { Network\#12 }\end{array}$ & $\begin{array}{l}\text { Mean } \\
\text { Thickness } \\
\text { Network\#14 }\end{array}$ & $\begin{array}{l}\text { Mean } \\
\text { Thickness } \\
\text { Network\#17 }\end{array}$ \\
\hline $\begin{array}{l}\text { Quick IQ } \\
\text { score }\end{array}$ & -0.20 & 0.17 & 0.31 & 0.03 \\
\hline $\begin{array}{l}\text { SSPI Reality } \\
\text { Distortion }\end{array}$ & -0.08 & 0.23 & 0.21 & 0.23 \\
\hline $\begin{array}{l}\text { SSPI Total } \\
\text { Delusions }\end{array}$ & -0.02 & 0.16 & 0.05 & 0.32 \\
\hline Hallucinations & -0.03 & 0.26 & 0.21 & 0.20 \\
\hline
\end{tabular}

None of the above results are statistically significant at an uncorrected $p=0.05$ threshold. 


\section{Figure S1: Yeo 17 network parcellations}

This figure is obtained from https://balsa.wustl.edu/W8wK. The labels are based on the original description of Yeo's 17-netorks parcellation provided at https://surfer.nmr.mgh.harvard.edu/fswiki/CorticalParcellation Yeo2011.

The naming convention and regional description as per Baker (2014) is displayed in Table 2.

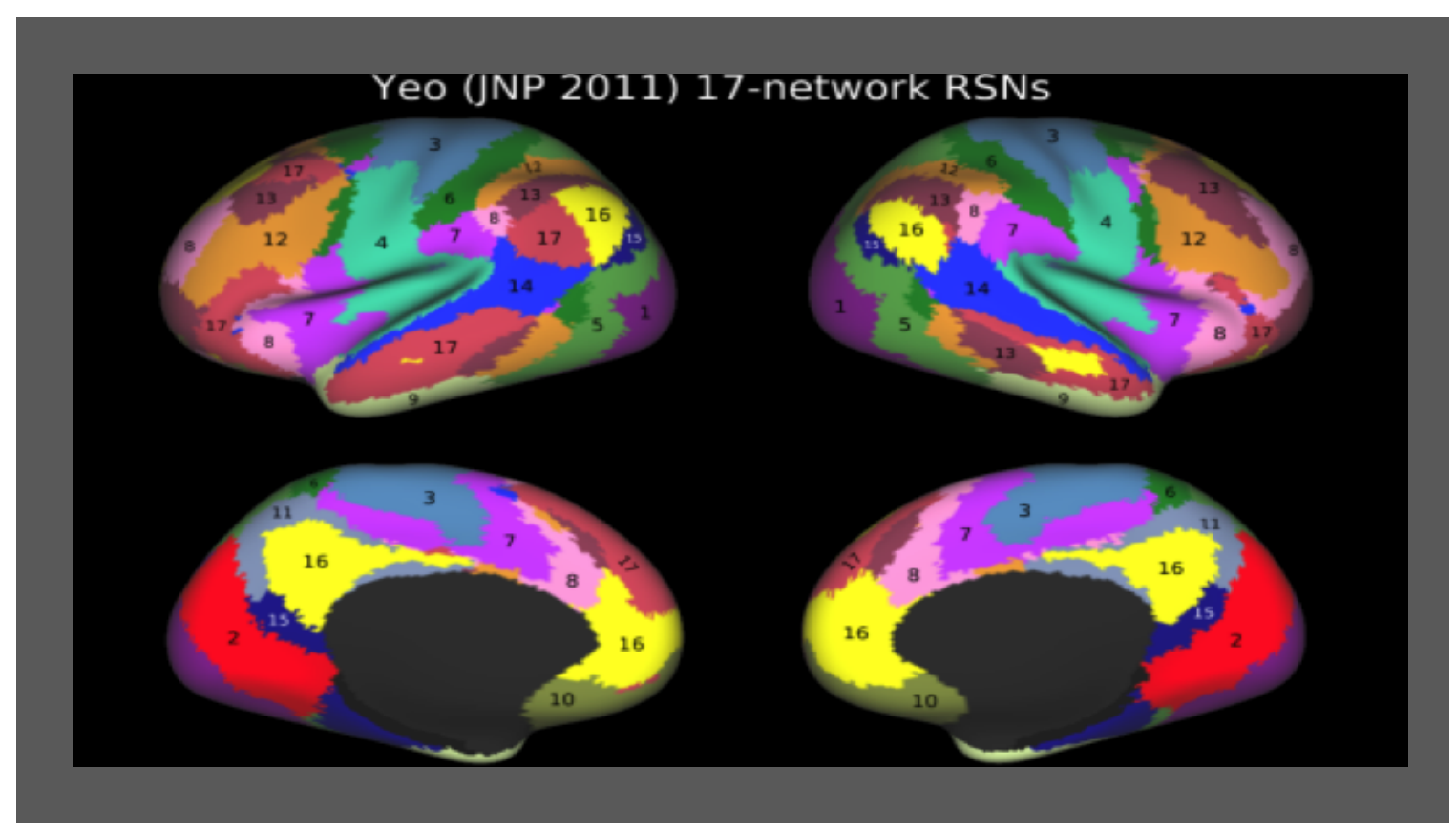


Conflicts of interest: LP reports personal fees from Janssen, Otsuka Canada, Canadian Psychiatric Association and SPMM Course (UK); investigator-initiated educational grants from Sunovion, Janssen Canada, Otsuka Canada not related to the submitted work. Other authors report no relevant conflicts. 
Cortical thickness and formal thought disorder in schizophrenia

\section{Ethics}

All subjects were recruited from the county of Nottinghamshire, UK with informed consent to participate obtained in accordance with the approval from the National Research Ethics Committee, Nottinghamshire. NHS REC Ref: 10/H0406/49 


\section{Contributors}

Data reported here was collected as a part of doctoral study of LP. The hypothesis tested in this study was conceived by LP who undertook the statistical analysis. All the authors have participated and have made substantial contributions to this paper: LP \& PFL: recruitment, clinical data collection, analysis, interpretations of data and preparing the manuscript. AA and PAG: imaging data collection, analysis, interpretations of data and preparing the manuscript. 